\title{
Tribochemistry as an Alternative Synthesis Pathway
}

\author{
Hayden Carlton ${ }^{1}$, David Huitink ${ }^{1, *}$ and Hong Liang ${ }^{2}$ \\ 1 Department of Mechanical Engineering, University of Arkansas, 863 W. Dickson St., Fayetteville, AR 72701, \\ USA; hscarlto@uark.edu \\ 2 J. Mike Walker Department of Mechanical Engineering, Texas A and M University, 100 Mechanical \\ Engineering Office Building, College Station, TX 77843, USA; hliang@tamu.edu \\ * Correspondence: dhuitin@uark.edu
}

Received: 30 May 2020; Accepted: 28 August 2020; Published: 29 August 2020

\begin{abstract}
While reactions driven by mechanical force or stress can be labeled mechanochemical, those specifically occurring at a sliding interface inherit the name tribochemical, which stems from the study of friction and wear: tribology. Increased perception of tribochemical reactions has been gained through technological advancement, and the development of new applications remains on-going. This surprising physico-kinetic process offers great potential in novel reaction pathways for synthesis techniques and nanoparticle interactions, and it could prove to be a powerful cross-disciplinary research area among chemists, engineers, and physicists. In this review article, a survey of the history and recent usage of tribochemical reaction pathways is presented, with a focus on forging new compounds and materials with this sustainable synthesis methodology. In addition, an overview of tribochemistry's current utility as a synthesis pathway is given and compared to that of traditional mechanochemistry.
\end{abstract}

Keywords: tribochemistry; mechanochemistry; tribology; surface chemistry

\section{Introduction}

The term mechanochemistry primarily describes the use of mechanical force to induce chemical reactions. Though perhaps the lesser-known branch of chemistry, mechanochemistry is easily one of the most ubiquitous. Several notable reviews have thoroughly encompassed key aspects of mechanochemistry from both a computational modeling and experimental research perspective [1-8]. While Michael Faraday was known for his documentation of the decomposition of $\mathrm{AgCl}$ through mechanical grinding in 1820 [9], the beginning of the modern study of mechanochemical reactions began in the late 19th century with the work of M. Carey Lea, who earned the title of "the father of mechanochemistry" with his foundational discoveries. In 1892, he was the first to systematically demonstrate the effects of mechanical force on activation energies [10]. His work introduced the concept that not only was mechanical input a viable equivalent to thermal energy, but the reaction mechanisms are also unique. An exhaustive review by Beyer et al. further developed this conclusion through showing numerous experimental instances of force dependency in published mechanochemical studies [1]. As such, mechanochemical reactions have been viewed in numerous critical reviews, surveys, and lectures as being a viable and sustainable synthesis methodology for future manufacturing endeavors and will aid the development of a new generation of chemistry [4,11-19]. Among the more attractive qualities of mechanochemical reactions is their inherent "green" and sustainable nature, due to the opportunity to reduce environmentally unfriendly solvents. For example, with an aspect of progressive research being sustainable solutions in drug development, pharmaceutical manufacturers have investigated mechanical processes for the development of active pharmaceutical ingredients (APIs) without the use of harmful solvents, which James et al. discuss in their review extensively [13]. 
Unlike traditional mechanochemistry, tribochemical reactions are those induced at a sliding interface primarily due to friction and surface rubbing; these interactions often result in the chemical formation of intermediate layers or "tribofilms", which are desirable in order reduce friction and wear [20-22]. Several factors distinguish tribochemistry from mechanochemistry, most notably the manner of energy dissipation. Tribochemical reactions primarily dissipate energy through shear at the contact between two surfaces, while mechanochemical processes (e.g., milling processes) induce reactions by dissipating energy into the bulk material (Figure 1).

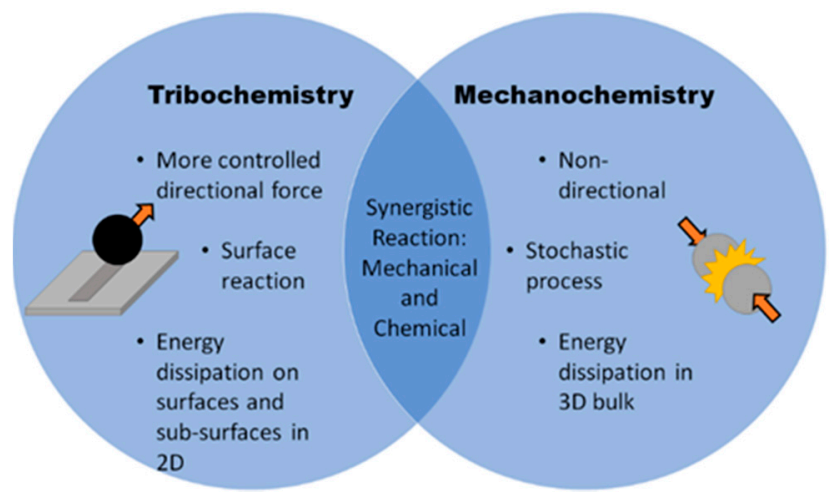

Figure 1. Direct comparison between tribochemistry and mechanochemistry.

As in the mechanochemical mechanistic understanding, tribochemistry utilizes externally applied work to affect the bonding energy of a material [23]. However, here, the energy released by the mechanical force in a sliding environment facilitates chemical bond breakage in the context of bond reformation with reactants, such that a decreased or supplanted activation energy associated with thermal kinetics can be accomplished. The chemical rate kinetics for a given mechanochemical/tribochemical reaction can be characterized by decreasing activation energy with increased externally applied stress (e.g., from rubbing two interfaces together) [24]; however, understanding how mechanical force accomplishes this is still highly experimental and unrefined. Unlike thermal energy, mechanical energy is much more complex due to its ability to be represented as a combination of both pressure and shear, as described by Boldyrev [2]; recent efforts have shown that shear stress rather than normal stress is a dominant driving factor in film formation [24]. With the aid of increased computational power, improved modeling capabilities, and novel characterization methods, tribochemistry has made the transition to a well-recognized, cross-disciplinary branch of chemistry. The popularity of tribochemistry over the past 50 years has increased rapidly, as indicated by the prevalence of technical articles depicted in Figure 2.

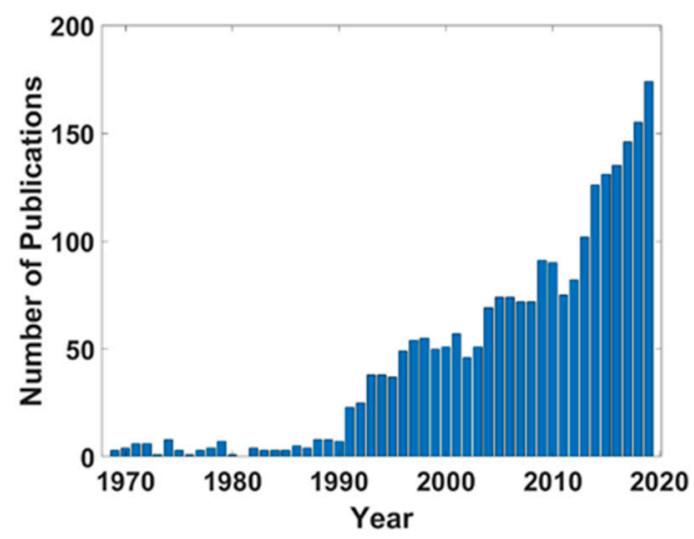

Figure 2. Publications with key words "tribochemistry", "tribochemical", or "tribo-chemistry" over the past 50 years, according to Web of Science [25]. 
The purpose of this review article is to analyse the current prospects for tribochemistry as an avenue for mechanical synthesis. Herein, we establish the current scope of mechanically induced reactions in both mechano- and tribochemistry. In addition to the overview, we provide examples of novel tribochemical synthesis in literature in order to inspire further advancement.

\section{Mechanochemical Synthesis}

Before delving into the potential of tribochemical synthesis, a precedent for mechanically activated reactions must be established. As mechanochemistry and associated fields have become further recognized as a sustainable alternative to many chemical processes, they have become more common place in large-scale manufacturing. A huge increase in attention regarding mechanochemical concepts has occurred within the past 10 years, and this has led to the development of an assortment of ingenious synthesis methodologies for materials using solvent-free methods [15]. Reviews such as those completed by Baláž et al. [4], James et al. [13], and Achar et al. [26] comprehensively discuss a myriad of inorganic and organic mechanochemical reactions and classify them based on the resulting products. These sections provide an overview of past and recent efforts in the field of traditional mechanochemical synthesis.

\subsection{Inorganic Compounds: Ceramics, Semiconductors, and Nanoparticles}

With many ceramics becoming more commonplace in industries such as aerospace or automotive, the ability to synthesize or modify them efficiently and effectively has become a high priority. Fabricating ceramics through ball milling continues to be a common way to create ceramic powders. Since most ceramics have high hardness and high melting points, they offer significant advantage over metallic and organic materials in high temperature conditions. $\mathrm{MoSi}_{2}$ maintains both of these properties, while also having a relatively low density, making it quite useful in the aerospace industry. In one prominent example, Ahmadabadi et al. discovered a method for creating $\mathrm{MoSi}_{2}$ via a ball milling procedure, and they noted that different phases of $\mathrm{MoSi}_{2}$ could be created based on the amount of aluminum that was introduced to the mill [27]. Engineered ceramics also have an established role in the medical industry as biocompatible materials. HAp, or $\mathrm{Ca}_{10}\left(\mathrm{PO}_{4}\right)_{6}(\mathrm{OH})_{2}$, is a ceramic used for implant fabrication, and a novel method for creating variations of HAp has been observed [28]. Ceramics with a high dielectric constant, such as $\mathrm{CaCu}_{3} \mathrm{Ti}_{4} \mathrm{O}_{12}$, can be created as well [29]. Ferroelectric ceramics, which are involved in manufacturing capacitors, sensors, and transducers, are also valued due to their high dielectric properties; high-energy ball milling is used to manufacture these materials into nano-powders from their oxidative precursors [29]. Along with ferroelectrics, ferromagnetic materials, used as permanent magnets and magnetic recording heads, form ultra-fine crystallites through mechanochemical activation. An example of this is the mechanochemical synthesis of $\mathrm{BaFe}_{12} \mathrm{O}_{19}$, which can be synthesized from ball milling after a co-precipitation process [30]. Mossbauer studies have also been performed on ferromagnetic materials that have high magnetization and anisotropy, such as $\mathrm{SrFe}_{12} \mathrm{O}_{19}$ [31]. Lanthanum hexaboride, $\mathrm{LaB}_{6}$, is used extensively in optical systems, as a refractory material; it can be synthesized via ball milling as well, due to its precise control, room temperature processing, and its simplicity [32]. Ceramic materials maintain a role in the pharmaceutical realm as well with layered double hydroxides as capable ion-exchangers; various methods, including simple mechanochemical and mechano-hydrothermal, can be used to manufacture these materials [33]. Mechanochemical techniques have also been explored in a few notable studies in the creation of ceramic powders and titanium. An early study by Chen et al. observed the creation of rutile $\left(\mathrm{TiO}_{2}\right)$ from ball milling ilmenite $\left(\mathrm{FeTiO}_{3}\right)$ through a sulfurization reaction induced by a planetary ball mill, where $\mathrm{FeS}_{2}$ and $\mathrm{TiO}_{2}$ were produced [34]. Rutile is a common source for titanium and is also used to manufacture $\mathrm{TiB}_{2}$, which is a common component in high-temperature coatings and crucibles [35]. A commonly processed material powder, zirconia $\left(\mathrm{ZrO}_{2}\right)$, was discovered to be produced from grinding zircon $\left(\mathrm{ZrSiO}_{4}\right)$ with alkali compounds such as $\mathrm{Ca}, \mathrm{Mg}, \mathrm{Ca}(\mathrm{OH})_{2}$, and $\mathrm{NaOH}$. The additives showed to render zircon more susceptible to react and created zirconia [36]. 
When considering semiconductor fabrication processes and the widespread use of electronics, sustainable and eco-friendly electronic fabrication and waste disposal represents an important and necessary development, for which mechanochemistry can assist. A recent example is the creation of indium arsenide (InAs), which is a renowned semiconductor material known for its electron transport properties, where Bujňáková et al. established a rudimentary mechanochemical process for creating InAs via a planetary ball mill [37]. In optoelectronics and semiconductors, chalcogenides, such as $\mathrm{Ga}_{2} \mathrm{Se}_{3}$ and $\mathrm{Ga}_{2} \mathrm{~S}_{3}$, have been fabricated from ball milling as well [38]; along with mechanochemical input, heat treatment is introduced into the manufacturing process as a two-step method to create a more uniform crystal structure. Other chalcogenides, such as $\mathrm{Cu}_{2} \mathrm{FeSnS}_{4}$ (stannite) and $\mathrm{Cu}_{2} \mathrm{ZnSnS}_{4}$ (kesterite), which have been proven in small scale application to be useful in the fabrication of photovoltaic cells, have been synthesized via ball milling [39]. Traditional fabrication of these materials involves the use of toxic precursors; however, with mechanochemical methodologies, this study further strengthens the sustainable nature of mechanochemical green synthesis.

Due to the ever-increasing demand for efficiency and performance of electronics, scaling efforts have led to the development of nano-scale electronics-also sparking the creation of nano-scale semiconductors. Mechanochemical methodologies have shown to be able to produce nanocrystalline compounds through the usage of high-energy ball milling [40,41]. In an effort to visualize these types of interactions, TEM electron diffraction and spectroscopic methods in conjunction with the in situ nanoindentation of a gold-coated indenter into crystalline Si facilitated the observation of the nucleation of an intermediate phase (gold silicide) at the interface of mechanical energy input [42] (Figure 3). The strain-based energy input offered through these methods enables reaction pathways that can form materials having unique electronic properties, for potential use as novel electronic materials.

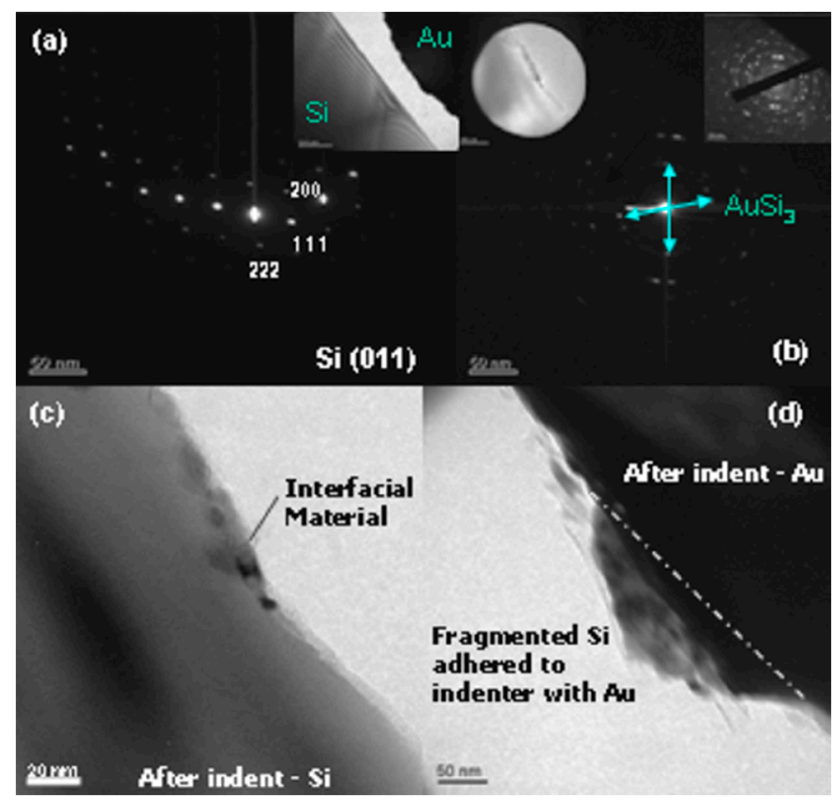

Figure 3. TEM and electron diffraction before and after indentation: (a) Si diffraction pattern prior to contact; (b) formation of new material; (c) Si after indentation; (d) Au after indentation. (Reprinted from [42]. Copyright 2020, with permission from AIP Publishing).

Recent nanoparticles fabricated through mechanical processes have shown antibacterial properties (e.g., Ag nanoparticles) [43] and success in bio-imaging applications, such as with chitosan-coated ZnS nanocrystals [44]. Mechanical-based synthesis also provides a means through which to functionalize nanoparticles as well, such as with carbon-coated iron nanoparticles [45]. Other nanoparticle catalysts, such as $\mathrm{TiO}_{2}$, have also been synthesized via mechanical methods [46]. The catalytic properties of $\mathrm{TiO}_{2}$ nanoparticles enable them to be incorporated into a variety of systems, such as in the study 
by Dunnill et al., where they were integrated into photocatalytic thin films [47], and for solar cell applications, where the nitrogen-doped nanoparticles improved the photoconversion properties of dye-sensitized solar cells [48]. Mechanochemical nanoparticle production has recently brought about additional advancements in creating nano-scale materials with enhanced magnetic properties such as $\mathrm{Cog}_{8} \mathrm{~S}_{8}$ [49], increased electrical energy storage in supercapacitors [50], as well as advancing the study of thin films for use in electronic devices [51]. For carbon nanotubes, metallic nanoparticles are often attached to their surface for use in sensors, catalysts, hydrogen storage, and to promote electromagnetic properties [52], and altered carbon nanotubes can be created through mechanical input [52]. Metal particles can also be attached to graphene nanoplatelets through mechanochemical methods [53] since graphene platelets are commonly used as anodes.

\subsection{Organic Compounds: Metal-Organic Frameworks and Co-Crystals}

Metal-organic frameworks (MOFs) represent a group of materials that are comprised of one, two, or three-dimensional lattices, which contain organic ligand linkers and inorganic nodes [54]. The materials share a common quality of also being quite porous and brittle crystalline materials. MOFs have extensive applications such as catalysis, separations, gas storage, and molecular recognition [55]. Mechanochemical synthesis reactions have been shown to produce MOFs effectively and efficiently with no solvent addition. Manual grinding and co-grinding of salts has shown to break down weak hydrogen and Van der Waal bonds to create novel organometallic crystalline lattices [56]. Mechanochemical MOF production is described with the statement "make crystals by smashing crystals"; this statement intuitively describes the milling process of MOF production and the development of these complex structures [57]. Kaupp describes this same process of interactions between crystalline materials in three separate stages: 1 . phase rebuilding, where the reacted molecules migrate to form crystal-correlated surface features, 2. phase transformation, where the product lattice discontinuously forms, and 3. disintegration with the formation of the new two-phase surface [58].

Co-crystals relate to MOFs in their role in the pharmaceutical industry. A great deal of metallodrugs and metallopharmaceuticals are generated on a daily basis through mechanochemical processing [59]. In the pharmaceutical industry, co-crystals are used extensively in drug manufacturing, and determining cleaner and more efficient ways of manufacturing these unique materials is key. The definition of a co-crystal is of somewhat of a debate amongst the academic community; perhaps the most prevalent usage of the word is used to describe pharmaceutical co-crystals, which are used for drug development [60]. The word arguably should mainly be used as a synonym for multi-component molecular crystal [60]. Co-crystals can be broken up into categories, such as charge transfer co-crystals [61], acid-base co-crystals [62], and ionic co-crystals [13,63]. Mechanochemical synthesis enables solvent-free methods for forming these useful compounds; however, mechanical grinding is not always the best method for co-crystal formation; sometimes grinding by itself can slow or inhibit the co-crystal formation without liquid-assisted grinding [64]. Mechanochemical synthesis is regarded in the pharmaceutical realm as the "green alternative" for synthesizing co-crystals [65]. An example has been shown through the formation of carbamazepine, an anti-convulsant and mood-stabilizer, co-crystals using a vibration ball mill and indometacin, benzamide, and nifedipine as the secondary crystals [65]. Ibuprofen/nicotinamide co-crystals have also shown to be created through mechanochemical means [66]. Liquid-assisted grinding is utilized in a different process, which creates homoallylic alcohols by mechanochemical allylation using potassium allyltrifluoroborate salt and water; potassium allyltrifluoroborate salt is a good substance to perform this procedure with because it generates inert, nontoxic, water-soluble salts [67]. In addition to removing the need for hazardous solvents, mechanochemical approaches can also result in almost $100 \%$ yield, which lessens the amount of purifying procedures needed [66]. Organic compounds are sometimes added to the milling processes to aid in production; this was observed when proteases were added to a ball mill to assist in the formation of peptide and amide bonds [68]. 


\section{Tribochemical Synthesis}

As the copious amount of research in this field of study indicates, mechanically induced synthesis has imbedded itself in numerous application areas, primarily through the advancement of milling methodologies; however, deviation from traditional milling techniques proves scarce in literature. This scarcity presents opportunity for tribochemical synthesis to be implemented outside of typical tribological applications. Historically, the extent of material synthesis via tribochemistry almost exclusively has focused on the lubrication industry (i.e., tribofilm formation, friction reduction, lubricity of materials, etc.). Notable areas of tribochemical research include engine additives, such as the popularized zinc dialkyl-dithiophosphate (ZDDP) $[69,70]$ and the development of solid lubricant coatings, like polytetrafluoroethylene (PTFE) [71]. Even though researching friction mitigation remains of the utmost importance in society, utilizing tribochemical processes in unconventional scenarios has proven successful in a few cases of demonstrating new and innovative material synthesis techniques. By directly applying tribological principles, advances in chemical compound synthesis and the fabrication of nanoscale materials are possible. The sections herein aim to both summarize the state of progress in the field of traditional tribochemistry, as well as introduce examples of novel tribochemical research.

\subsection{Driving Mechanisms of Tribochemical Reactions}

Due to the underlying complexities of tribochemical transformation, developing an "all-encompassing" theory or model has been elusive. The ability to directly observe mechanical energy input on the atomic level is limited to the use of in situ spectroscopies [72-75]; however, the translation of these observations into developing phenomenological models has been the goal of researchers since the mid-1950s. The first models started as rough qualitative representations, while more recent models have employed the use of increased computational power to implement quantum mechanical methods and computational molecular dynamics simulations to illustrate mechanical forces on a molecular level [7]. These techniques have allowed researchers to effectively model these interfaces, give insight into highly intricate processes, as well as predict reaction paths [76]. Regardless, most researchers in the field of tribology and tribochemistry understand that a variety of factors play important roles in driving tribochemical reactions, with the most notable being frictional heating, wear, applied force, and triboemission. All occur simultaneously during a tribochemical reaction and must always be considered when performing research in this field. The combination of these parameters comprises the uniqueness of tribochemistry, and also provides evidence as to why it is such a powerful route for material synthesis.

\subsubsection{Frictional Heating and Wear}

Frictional heating at the sliding interface plays a major role in driving tribochemical reactions. The interplay between local temperature and reaction rate is a well-established concept in chemistry, described by an Arrhenius relationship. In a traditional chemistry setting, measuring heat transfer within a solution or bulk material is trivial with properly placed temperature measurement equipment; however, determining the heat transfer due to friction at a sliding interface is less intuitive. In the realm of tribochemistry, frictional heating simply refers to the local rise in temperature as a result of the sliding contact between two surfaces [22]. In the case of perfectly smooth surfaces, generated stresses are distributed evenly across the entire area of contact; however, for real surfaces with a given roughness, energy is expelled through contacting asperities. Such contacts often result in the creation of high local temperatures, which exist on an incredibly short timescale. A temperature maximum, often referred to as the flash temperature, occurs when all the frictional power is dissipated through a single asperity [77]; the flash temperature and the local temperature of the sliding contact are intrinsically related and parallels are often drawn between the two in literature [78]. The flash temperature can be expressed in the form of the Blok-Archard equation (Equation (1)), where $T_{f}$ if the 
flash temperature, $T_{0}$ is the average temperature of the sliding body, $f$ is the friction coefficient, $v$ is the sliding velocity, $H$ is the hardness, $W$ is the load, and $k$ is the thermal diffusivity [22].

$$
T_{f}=T_{0}+\frac{f v \sqrt{\pi H W}}{8 k}
$$

The determination of the flash temperature for a specific tribochemical reaction provides insight into the magnitude of the heat transfer occurring at a sliding interface. One of the main challenges associated with this estimation is determining the actual area of contact during the reaction, which proves difficult. The true area of contact perpetually changes [79], which in turn alters the magnitude of heating due to friction. This makes modeling frictional interfaces computationally much harder since this area of contact changes with both speed and normal load [24].

Surface wear during a reaction also represents an important parameter to consider. Numerous material surfaces, particularly metallic and ceramic, possess heavily oxidized boundary layers, which separate the bulk material from the oxygen-rich atmosphere and remain largely chemically inert. Early research recognized that wearing away these exterior layers and continually exposing the fresh material underneath resulted in accelerated tribochemical reactions [22]. For example, iron surfaces uncovered from wear enhanced the decomposition of the widely used lubricant additive ZDDP [80]. More recent examples in literature also corroborate these observations, such as how freshly scratched gold surfaces resulted in enhanced chemisorption [81], as well as how nascent steel surfaces could induce the formation of iron phosphide tribofilms [82]. In short, continuous mechanical perturbation at a sliding contact constantly generates new reaction surfaces and thermal loads, and surfaces that are atomically "clean" have been shown to greatly encourage tribofilm formation.

\subsubsection{The Role of Force}

Kauzmann and Eyring provided one of the first models to represent the effects of an external force on bond strength [83]. In their discussion of viscous flow, the effect of shearing force on large polymers was examined in terms of their bond energy, represented as a Morse potential (Figure 4). The illustration shows the strength of the unperturbed bond being represented as D, or the amount of energy necessary to induce bond breakage; however, an applied force, represented by the dashed line, essentially stretches the bond and deforms the potential, which results in a lower dissociation energy, D' (i.e., less energy needed to break the bond). Similarly, mechanical perturbation also encourages bond formation. The influence of mechanical force in both bond breakage and formation-as well as the interplay between the two-is one of the driving forces behind tribochemical synthesis.

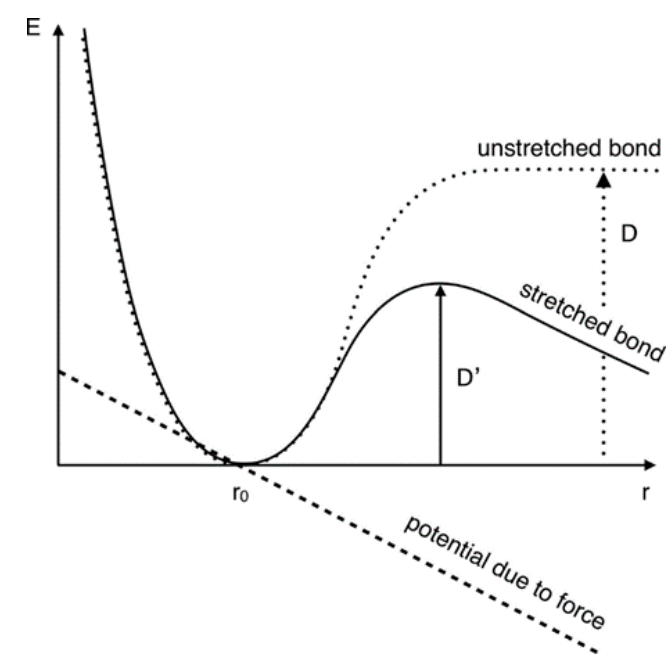

Figure 4. External force reduces unperturbed bond strength. (Reprinted with permission from [3] and adapted from [83]. Copyright 2020 American Chemical Society). 
Extending upon this idea of mechanically altering bonds, Bell created an Arrhenius-type expression to represent how an applied external force modified a bond's lifetime and activation energy barrier [84]. The equation that Bell postulated is shown in Equation (2), which determines the lifetime of a bond $(\tau)$ in terms of applied force $(F)$ and temperature $(T)$, where $\tau_{0}, E_{0}$, and $\gamma$ are all constants of the material. Through this model, the activation energy varies linearly with the applied external force. The uniqueness of Bell's 1st-order model stems from its simplicity; rather than focusing on the perturbations of the geometry or potential energy surface of the system, it represents force solely as its effect on the activation energy. After the development of the original Bell methodology, several attempts at improving its accuracy and computational reliability began to emerge, including the Bell-Evans model [85], the extended Bell model (incorporating 2nd-order accuracy) [86], and the Bell-Taft model, which took into account steric hindrance caused by mechanical input [87].

$$
\tau=\tau_{0} e^{\frac{E_{0}-\gamma F}{k T}}
$$

In terms of its predictive modeling performance, the Bell models produce results of acceptable accuracy [88]; however, there remains room for improvement. Mechanical energy's role in chemical reactions increases in complexity with more advanced geometries and force systems, and the simplicity of the Bell ideology can cause the model to be inadequate, which makes choosing the Bell model parameters paramount in producing valid results [89-91]. A notable attempt to deviate from the Bell-centred methodology is the tilted potential energy surface model for describing non-covalent reactions [6,92,93]. Unlike the Bell model, the tilted model can consider the non-linear behavior of the transition state; thus, their positions along the energy profile can be predicted.

\subsubsection{Triboemission at the Interface}

Tribochemical reactions represent a unique hybrid group of reactions types, due to the presence of both thermal and mechanical loads. Most commonly, thermal loads at an interface consist primarily of frictional heating associated with a rubbing or sliding contact; however, this heat represents just a small portion of the underlying interactions taking place at the interface. The previous section focused primarily on the deformation of chemical bonds to reduce activation energy; however, the intense mechanical forces endured by reactants often result in emission of particulate or energy from the interface, which inherit the name "triboemissions" [94]. While most efforts focus solely on the emission of electrons, triboemissions often comprise several natural phenomena from heat to photon emission, as shown in Figure 5.

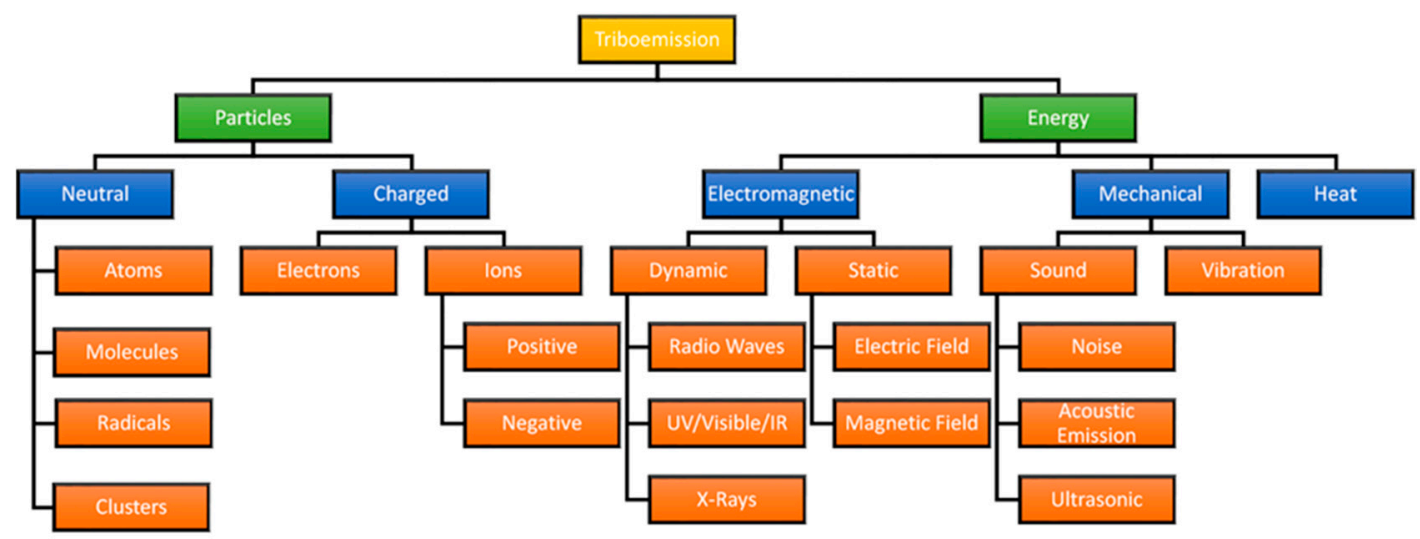

Figure 5. Classifications of different types of triboemission (Adapted from [95,96]).

Initially, these emissions were assumed to be a result of simply increased temperature at the interface [97]. From the Richardson-Dushman equation, electron emission from a surface shows 
to be largely a function of temperature and a material's work function. If that hypothesis proved accurate, then many experimental studies of triboemission could be duplicated by simply increasing localized temperature. On the contrary, several early studies indicated a heavy dependence of triboemission on the wear associated with surface scratching $[98,99]$, which alluded to the idea that triboemissions occurred athermally [100]. Exoelectron triboemisssions from within the wear track are largely recognized as one of the driving forces behind tribochemical reactions, such as instances of lubricant breakdown and tribofilm formation [95] and can even promote the degradation of protective films on the atomic level [101].

A notable theory that describes the origin of triboemissions, such as exoelectrons stems from the idea of fracto-emission [102]; many researchers postulate that during cracking and subsequent material failure, particles such as electrons and photons are emitted. Often at a sliding interface, microcracks develop within a surface simply due to the effects of friction and wear; surface charges can accumulate along the edges of these cracks, resulting in charge separation, electric field formation, and eventual emission of electrons [103]. Several factors impact the degree to which fracto-emission occurs. Obviously, the degree of wear plays an important role, such that triboemission varies with the severity of wear on a surface, but other parameters such as degree of oxidation, electrical resistivity, as well as environmental conditions also impact triboemission flux from a wear surface [94,95]. Experimental observations indicate that surface oxidation plays a pivotal role in triboemission, such that triboemission processes occurred more readily on wear surfaces that were heavily oxidized [94]. It becomes increasingly apparent that understanding the impact of triboemissions is a large piece of the puzzle that elucidates the driving force behind tribochemical reactions. While many of the theories show promise in properly characterizing these unique chemical reactions, much uncertainty exists. Further efforts and more encompassing models using modern computational power are necessary to expand these theories into more practical applications such as material synthesis.

\subsection{Molecular Dynamics in Tribochemistry (in Brief)}

A renaissance of computational advancement over the past few decades has ushered in a new age of reaction modeling. Molecular dynamics (MD) continues to be utilized in atomistic scale tribochemical simulations to actively represent bond scission as well as the synthesis of new materials at a sliding interface. Martini et al. published an encompassing review covering these types of simulations in tribochemistry, such as reactions within a lubricant [7]; as such, a broad discussion of these simulations is outside the scope of this review. Tribochemistry research often utilizes both reactive and ab initio MD simulations to simulate a coating or lubricant for a particular application [104]. The time and length scale of MD allows for the in situ observation of tribofilm formation. Conversely, mechanically induced decomposition of materials can be determined as well, such as the study performed by Adams et al. regarding the decomposition of methyl thiolate at a sliding interface [105].

The potential energy of a realistic system dynamically changes under environmental, internal, and external energy impulses, especially when perturbed mechanically. Because mechanical input changes both the physical geometry of the molecular structure and can introduce heat and mass transport, the subsequent changes to potential energy are best explored using MD when considering mechanochemical and tribochemical reactions. In order to effectively show how perturbations in the atoms' geometry affect the activation energy, quantum mechanical algorithms are used to show the interatomic as well as the external forces. These tools enable researchers to explore potential new reaction pathways for developing novel engineered materials and interfaces, particularly as algorithms mature with integration of multi-factor energetic contributions. 


\subsection{Tribofilm Formation}

As one of the fundamental occurrences in tribochemistry, tribofilm formation simply refers to a layer of material formed at a sliding contact as a result of interfacial chemical interactions [106]. Traditionally, researchers target film formation as a unique way to reduce friction and prolong engine lifetime; this is typically achieved by introducing novel additives at the sliding interface. This section seeks to give a brief overview of traditional tribochemical research, particularly with the materials involved in the formation of tribofilms.

Research involving the capacity of tribofilms to improve engine efficiency predates this review effort by many decades. With nearly all mechanical components requiring some form of friction mitigation, lubricants are arguably the most important aspect of a mechanical system. Maximizing their performance has been an active research topic since the mid-20th century, particularly with the usage of oil additives. These oil additives, when succumbed to the high temperature and pressure of an engine environment, form chemically stable layers of sacrificial material (tribofilms), which reduces surface wear and prolongs engine life. Among the first of these additives, which is still being used today, is ZDDP, discussed briefly in previous sections; early review articles provide extensive background regarding ZDDP structure, formation, and performance $[69,70]$. Used as an additive to vehicle engine oil, ZDDP is revered for its ability to form stable tribofilms that are quite wear resistant [107]. A myriad of evidence in literature highlights the friction reduction properties of ZDDP. A recent atomic force microscopy study monitored the growth of ZDDP tribofilms and the associated reduction in the coefficient of friction [108]. An additional effort attempted to bridge the gap between simulated and experimental results through the development of a predictive wear model [109]. However, even though the extent of ZDDP's protective properties is well known, much is unknown about the in situ reaction kinetics [70]. Nicholls et al. provides a synopsis of proposed film formation mechanisms in their review; they observe that the biggest controversy with ZDDP is the mechanism through which the polyphosphate film forms [69]. With an increase in modern computational ability, researchers can attempt to resolve these controversies by providing a glimpse of the chemical interactions which take place at the sliding interface, such as an effort by Onodera et al., which showcased the wear prevention ability of a ZDDP tribofilm through the simulated digestion of an iron oxide wear particle (Figure 6) [110].

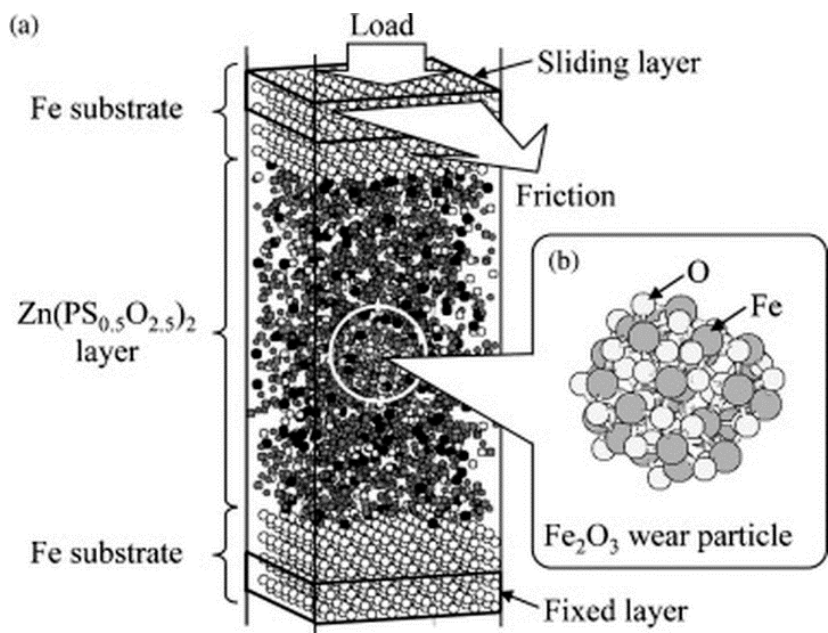

Figure 6. Molecular dynamics simulation of how zinc dialkyl-dithiophosphate (ZDDP) behaves with iron oxide wear particulate. (Reprinted from [110]. Copyright 2020, with permission from Elsevier). 
Researchers observed that the polyphosphate tribofilm, created by chemical interactions between ZDDP and the contact surface, was responsible for the wear and friction-reducing properties of ZDDP additives. Eventually, tribologists attempted to replicate the tribofilm by introducing polyphosphate additives directly; these new lubricants adopted the wear-reducing properties of normal ZDDP lubricants, while simultaneously being more environmentally friendly (due to the lack of heavy metal ions) [111]. When tested experimentally, these new glassy polyphosphate lubricants at a steel/steel contact observed high thermal stability, a 60\% decrease in friction, and a 59\% reduction in wear volume, according to one study [112].

In addition to work with polyphosphate films, much attention has been given to carbonaceous films, which have been shown to possess admirable tribological properties. Early carbon films consisted of diamond-like carbon, which have high scratch resistance. These films are generally deposited through physical or chemical means prior to use [113]; however, the prospect of creating these carbon films in situ continues to be a hot research topic [114-116]. Similar to tribofilms created by ZDDP additives, intense heat and pressure at a sliding interface encourages interactions between the lubricant and contact surfaces to generate carbon-based films. A notable study by Erdemir et al. examined the formation of such tribofilms; their effort incorporated both experimental and computational data and illustrated carbon film formation from the base oil interacting with a chemically active crystalline surface [104].

\subsection{Novel Tribochemical Synthesis}

Tribochemistry offers much utility as a synthesis technique due to its synergistic nature and directional control; however, the bulk of published works primarily focus on improving wear and reducing friction, rather than purely synthesis. The following section provides a few examples of novel tribochemical synthesis efforts in literature and encourages researchers to explore tribochemical reactions as a route for creating new and exciting materials through frictional environments.

\subsubsection{Direct-Write Synthesis of Carbonaceous Materials}

With carbon-based nanomaterials generating significant interest from the academic community over the past decade, it is necessary to create new and ingenious ways of fabricating these versatile materials. In the previous section, work by numerous researchers showcased the capability for tribochemical methodologies to generate thin carbon-based films at a sliding interface, which could prove useful for the direct-write fabrication of high-aspect ratio carbon structures. Direct-write synthesis is not a new concept, with several examples existing in literature [117-119]; it mainly refers to the synthesis of a material in a controlled pattern. These direct-write methods most often require advanced techniques such as the use of an electron beam, which are often expensive and inconvenient. Tribochemical approaches have the potential to deliver similar results as standard direct-write methodologies by taking advantage of mechanical sliding as the primary energy input. Such a tribochemical approach was demonstrated for synthesizing functionalized graphene platelets directly at the graphite/silicon interface with hydrazine [100]. A later study would expand upon these efforts by performing a similar experiment but with platinum nanoparticles acting as both mechanical and chemical exfoliants for the graphite [120]; the resulting graphitic deposits from this study are shown in Figure 7.

Both methods displayed simple tribochemical methods for creating high aspect ratio carbonaceous formations with a relatively inexpensive setup and atmospheric pressure environment. With many researchers utilizing graphene for advancements in areas such as flexible electronics [121,122], the ability to deposit graphene with extreme precision is paramount, and direct-write methodologies could prove to aid in their development. 

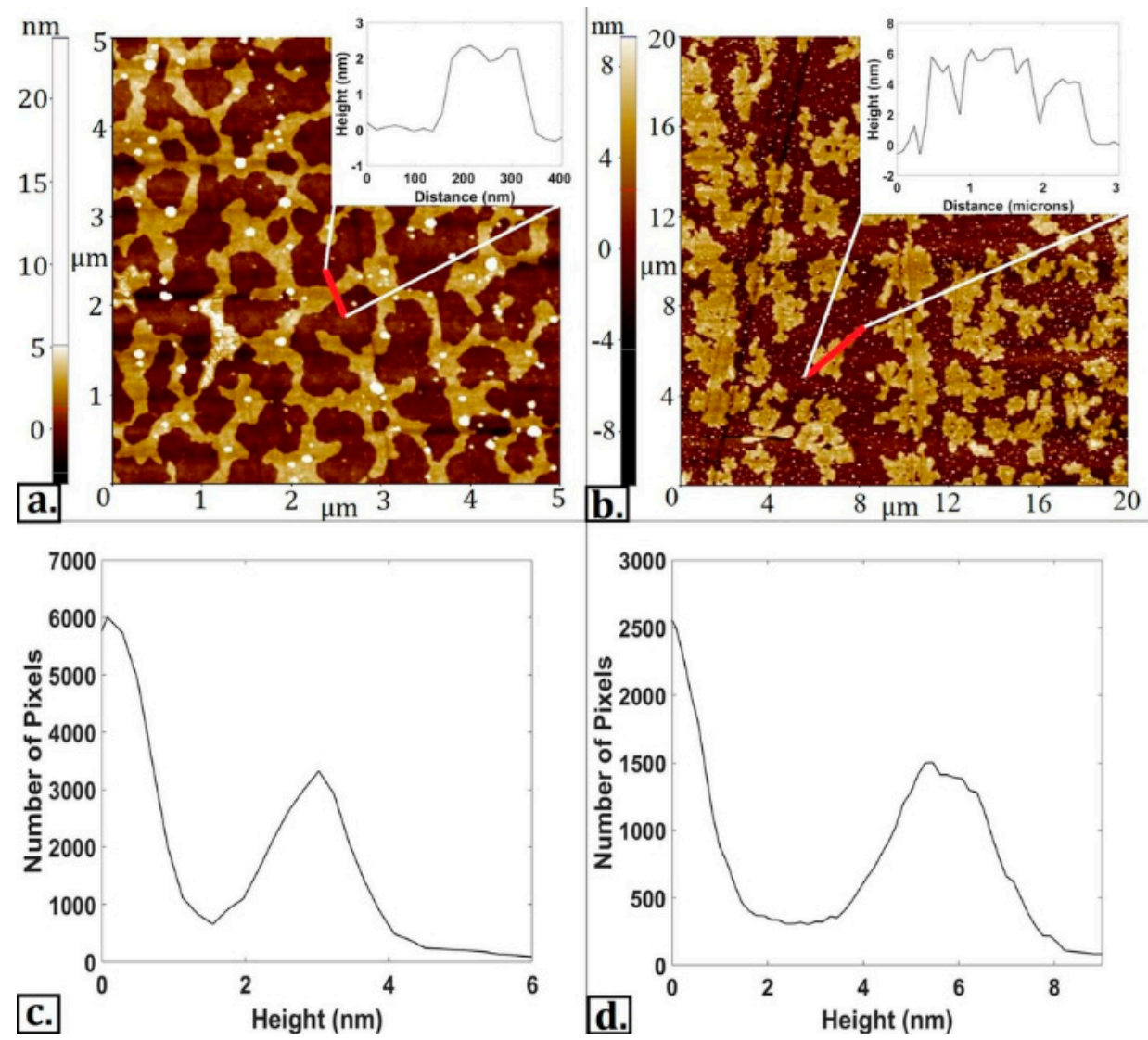

Figure 7. (a,b) AFM topographical scans of 1-3-layer graphitic formations on a silicon substrate via tribochemical reactions; (c,d). Height histograms of deposited material. (Reprinted from [120]. Copyright 2020, with permission from Elsevier).

\subsubsection{Nano Structure Fabrication}

In the field of tribology and tribochemistry, nanomaterials are largely studied based on their ability to enhance lubricity at a sliding interface. Such examples in literature include nano-sized carbon additives [123], as well as inorganic additives [124,125], and, as seen in the previous section regarding tribofilms, the in situ tribochemical formation of nanomaterials onto a surface is a common theme in this area of study, such as with the creation of nano-sized carbon [126]. With the obvious capability for the tribochemical synthesis of nanomaterials, its usage outside of conventional tribological applications remains scarce. Few works harness the multi-physical nature of a sliding contact as a force of synthesis rather than to just enhance tribological properties. One such example in literature utilized sliding contacts to synthesize silver nanochains through the breakdown of crown ether (Figure 8) [127]. The researchers surmised that the force exhibited at the sliding contact not only was responsible for driving the chemical synthesis reaction but also "guided the reaction paths for the formation" of the silver nanochains [127]. Such novel pathways toward alternative nano-structures presents interesting opportunities for the development of catalytic nanomaterials and locally controlled reactions. 
a
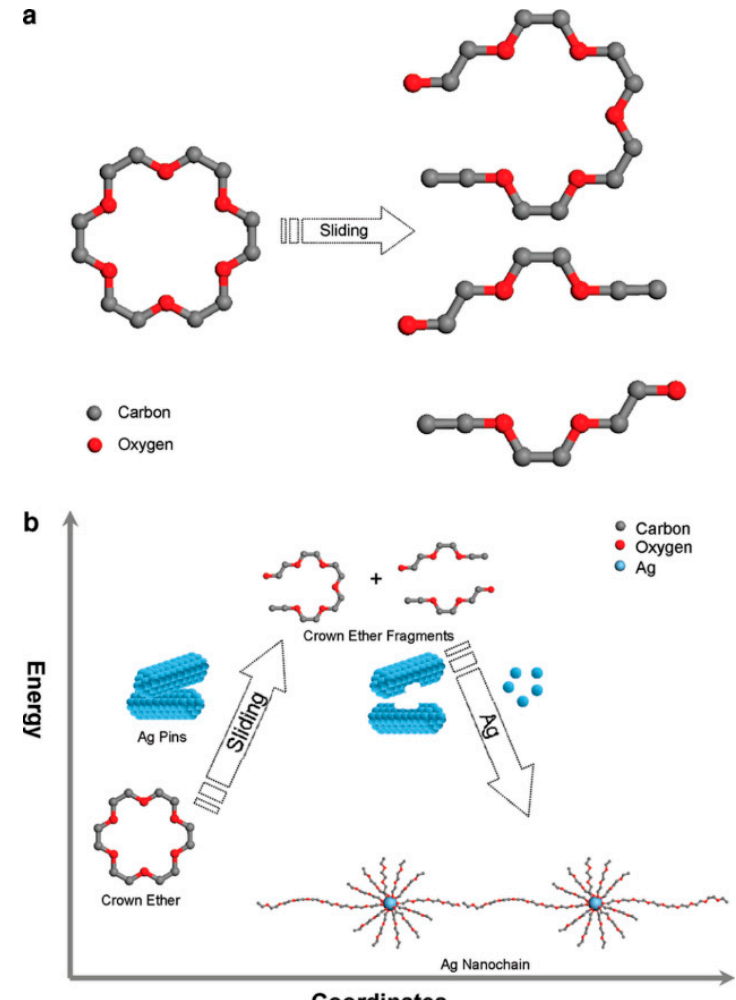

Coordinates

Figure 8. (a). Molecular dynamics (MD) simulation of crown ether breakdown due to mechanical stress; (b). Illustration of silver nanochain formation. (Reprinted with permission from [127]. Copyright 2020 American Chemical Society).

\subsubsection{Tribopolymerization}

Beyond particle and structural augmentation in tribosynthesis, the above reactions also hint at polymerization reactions taking place in the sliding environment. The term tribopolymerization simply refers to a polymerization reaction occurring due to the high pressure and temperature associated with a sliding interface. In terms of lubricity and wear reduction, tribopolymerization reactions are seen as a favourable occurrence; these reactions promote better surface adherence and improved reliability [128]. On the contrary, when discussing mechanical action on much smaller length scales, particularly with microelectromechanical systems, tribopolymerization, in some cases, induces device failure by reducing electrical conductivity [129].

While tribopolymerization research covers many decades, recent works have enhanced the understanding behind the mechanisms of tribopolymerization. Notable contributions within the past five years highlight aspects such as the uniqueness of mechanically induced polymerization reactions [130], how surface reactivity and oxidative gases enhance tribopolymerization [131,132], as well as tribopolymerization occurring among physisorbed molecules [133]. In the case of surface reactivity, Figure 9 provides an energy diagram representation of how mechanical input at a sliding interface enhances tribopolymerization reactions at both reactive and unreactive surfaces. In this particular study, the researchers found that surfaces with enhanced reactivity (i.e., surfaces capable of chemisorption without mechanical assistance) resulted in lower critical activation volumes and higher overall yield than unreactive surfaces [131]. Additional efforts include the in situ synthesis of nanocomposite tribofilms through tribopolymerization; these examples outline the formation of such tribofilms through the addition of nanoparticles such as $\mathrm{Cu}[134,135]$ and $\mathrm{WS}_{2}$ [136]. Polymerization reactions induced at a sliding interface expands the realm of possibilities for synthesis research. 

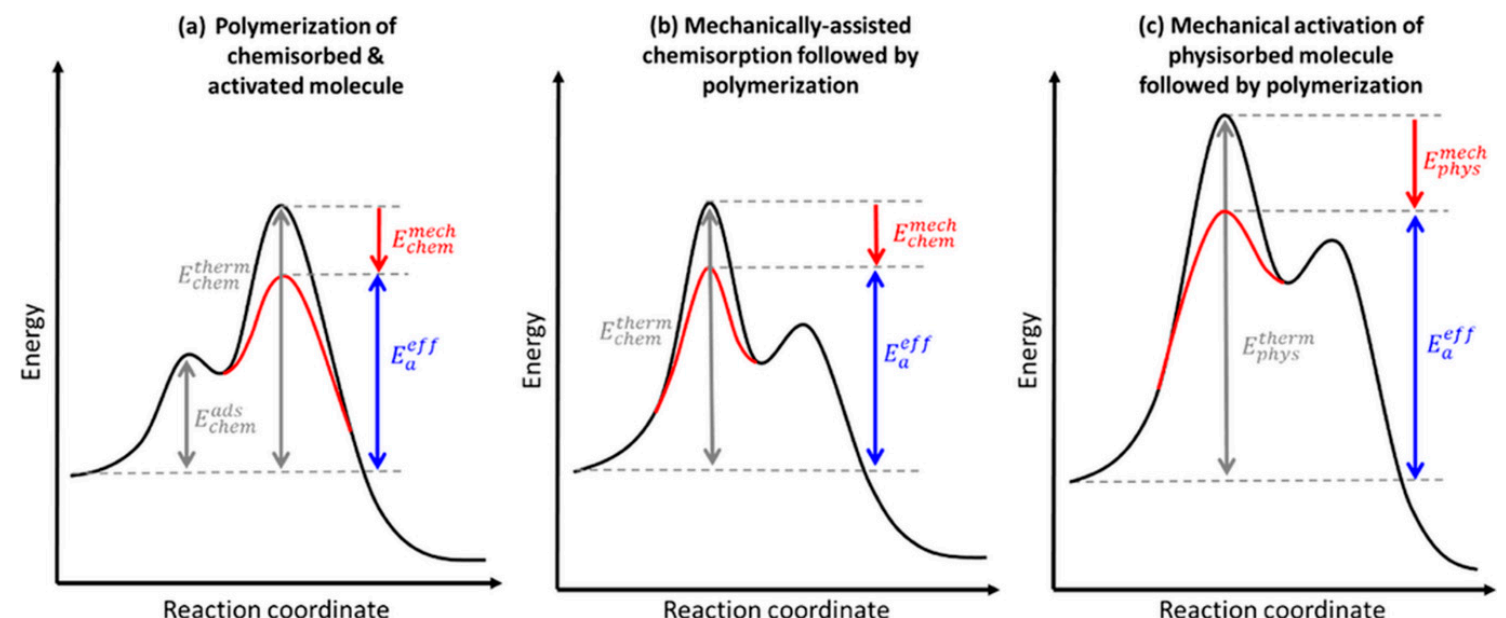

Figure 9. Representative energy diagrams for tribopolymerization reactions occurring at reactive and unreactive surfaces: (a) reactive surface where molecules undergo chemisorption and then mechanical activation; (b) reactive surface with mechanically induced chemisorption; (c) unreactive surface with physisorbed molecules that are mechanically activated. (Reprinted with permission from [131]. Copyright 2020 American Chemical Society).

\section{Advantage of Tribochemistry and Concluding Remarks}

As implied by the sections above, the attractive quality of tribochemical synthesis is the enhanced level of control, as compared to mechanochemical synthesis. Traditional mechanochemical methodologies leverage processing workhorses such as ball mills [137-139] and extruders [140-142]; milling is a batch process where the synthesized materials must be separated from other reaction products before being further refined, which can be impractical for many applications. Tribochemical approaches offer an advantage by initiating reactions within a predefined area (i.e., within the wear track) and depositing materials directly onto a surface, thereby reducing the required post-processing. Moreover, perhaps the most important benefit of tribochemical synthesis resides in the enhanced control over the direction of the applied force. Milling processes are inherently stochastic and rely on the probability of impacts to provide the necessary mechanical force to initiate a reaction. As a result, efficiency is lost through stray ball impacts that do not act along the reaction coordinate and thus may not participate in lowering reaction activation energy. A sliding contact offers precise and accurate control over force direction and can therefore be used to direct the force along the reaction coordinate to improve overall reaction efficiency. Such directional control of force and stress places tribochemistry at an advantage over mechanochemistry and allows for new applications to be pursued. For instance, the precise application of stress to alter electron pathways through a gold film (Figure 10) [143] illustrates novel opportunities offered by preferred forcing reactions. Furthermore, when used in conjunction with preferential surface topography and additively defined surfaces, tribochemical reactions could be enhanced or augmented using combined directional forces with directional manufacturing at interfaces [144]. Overall, the advantage of tribochemistry lies in its regulation parameters, such as direction, contact pressure, and sliding speed, which ultimately results in a more controlled reaction. 

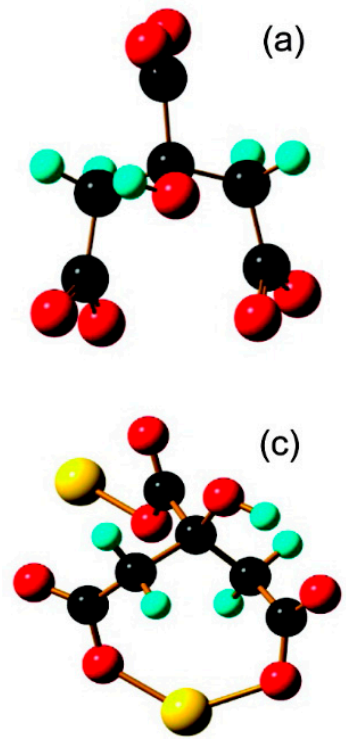

(b)

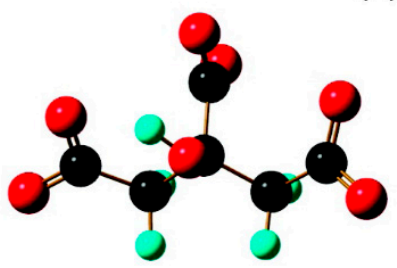

(d)

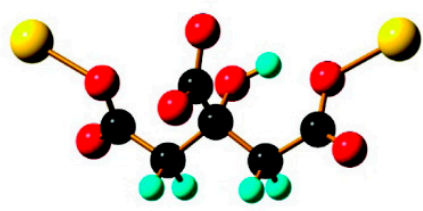

Figure 10. Two conformers of 2-hydroxypropane-1,2,3-tricarboxylate. Used in experimental and theoretical analysis to measure effect of stress on electron transmittance within a self-assembled gold nanoparticle film (a). Standalone Citrate-1 and (b). Citrate-2; extended (with one-gold-atom electrodes) (c). Citrate-1 and (d). Citrate-2. (Reprinted with permission from [143]. Copyright 2020 American Chemical Society).

Incorporating tribochemical concepts currently researched in the study of friction and wear could prove useful in expanding the current mechanochemical synthesis repertoire. Existing research indicates that applied mechanical force at a sliding interface can fabricate nanoscale materials through direct-write synthesis techniques, enhance current nanoparticle development, and enable polymerization; yet, enormous opportunity subsists in the other aspects of mechanochemistry currently dominated by milling techniques. While direct control of these reactions is still difficult and issues with product purification and scalability come into effect, as computational and characterization methods improve, the next generation of tribochemically synthesized materials is imminent. Tribochemical synthesis will continue to be optimized through better understanding, which will be achieved through fundamental investigations into the physics, chemistry, and mechanics of solids, from which a host of new materials and applications may emerge.

Funding: This research was supported in part through the University of Arkansas, College of Engineering, but not through any specific grant from funding agencies in the public, commercial, or not-for-profit sectors.

Conflicts of Interest: The authors declare no conflict of interest.

\section{References}

1. Beyer, M.K.; Clausen-Schaumann, H. Mechanochemistry: The mechanical activation of covalent bonds. Chem. Rev. 2005, 105, 2921-2948. [CrossRef] [PubMed]

2. Boldyrev, V.V. Mechanochemistry and mechanical activation of solids. Uspekhi Khimii 2006, 75, $203-216$.

3. Stauch, T.; Dreuw, A. Advances in Quantum Mechanochemistry: Electronic Structure Methods and Force Analysis. Chem. Rev. 2016, 116, 14137-14180. [CrossRef] [PubMed]

4. Balaz, P.; Achimovicova, M.; Balaz, M.; Billik, P.; Cherkezova-Zheleva, Z.; Criado, J.M.; Delogu, F.; Dutkova, E.; Gaffet, E.; Gotor, F.J.; et al. Hallmarks of mechanochemistry: From nanoparticles to technology. Chem. Soc. Rev. 2013, 42, 7571-7637. [CrossRef] [PubMed]

5. Caruso, M.M.; Davis, D.A.; Shen, Q.; Odom, S.A.; Sottos, N.R.; White, S.R.; Moore, J.S. Mechanically-Induced Chemical Changes in Polymeric Materials. Chem. Rev. 2009, 109, 5755-5798. [CrossRef]

6. Ribas-Arino, J.; Marx, D. Covalent Mechanochemistry: Theoretical Concepts and Computational Tools with Applications to Molecular Nanomechanics. Chem. Rev. 2012, 112, 5412-5487. [CrossRef] 
7. Martini, A.; Eder, S.J.; Dorr, N. Tribochemistry: A Review of Reactive Molecular Dynamics Simulations. Lubricants 2020, 8, 44. [CrossRef]

8. Tan, D.; Garcia, F. Main group mechanochemistry: From curiosity to established protocols. Chem. Soc. Rev. 2019, 48, 2274-2292. [CrossRef]

9. Takacs, L. The mechanochemical reduction of $\mathrm{AgCl}$ with metals. J. Therm. Anal. Calorim. 2007, 90, 81-84. [CrossRef]

10. Takacs, L.M. Carey Lea, the first mechanochemist. J. Mater. Sci. 2004, 39, 4987-4993. [CrossRef]

11. Do, J.L.; Friscic, T. Mechanochemistry: A Force of Synthesis. ACS Cent. Sci. 2017, 3, 13-19. [CrossRef] [PubMed]

12. Friscic, T. New opportunities for materials synthesis using mechanochemistry. J. Mater. Chem. 2010, 20, 7599-7605. [CrossRef]

13. James, S.L.; Adams, C.J.; Bolm, C.; Braga, D.; Collier, P.; Friscic, T.; Grepioni, F.; Harris, K.D.M.; Hyett, G.; Jones, W.; et al. Mechanochemistry: Opportunities for new and cleaner synthesis. Chem. Soc. Rev. 2012, 41, 413-447. [CrossRef] [PubMed]

14. Jones, W.; Eddleston, M.D. Introductory Lecture: Mechanochemistry, a versatile synthesis strategy for new materials. Faraday Discuss. 2014, 170, 9-34. [CrossRef]

15. Varma, R.S. Greener and Sustainable Trends in Synthesis of Organics and Nanomaterials. ACS Sustain. Chem. Eng. 2016, 4, 5866-5878. [CrossRef]

16. Wang, G.W. Mechanochemical organic synthesis. Chem. Soc. Rev. 2013, 42, 7668-7700. [CrossRef]

17. Tsuzuki, T.; McCormick, P.G. Mechanochemical synthesis of nanoparticles. J. Mater. Sci. 2004, 39, 5143-5146. [CrossRef]

18. Huot, J.; Ravnsbaek, D.B.; Zhang, J.; Cuevas, F.; Latroche, M.; Jensen, T.R. Mechanochemical synthesis of hydrogen storage materials. Prog. Mater. Sci. 2013, 58, 30-75. [CrossRef]

19. Friscic, T.; Mottillo, C.; Titi, H.M. Mechanochemistry for Synthesis. Angew. Chem. Int. Ed. 2020, 59, 1018-1029. [CrossRef]

20. Hsu, S.M.; Zhang, J.; Yin, Z.F. The nature and origin of tribochemistry. Tribol. Lett. 2002, 13, 131-139. [CrossRef]

21. Neville, A.; Morina, A.; Haque, T.; Voong, Q. Compatibility between tribological surfaces and lubricant additives-How friction and wear reduction can be controlled by surface/lube synergies. Tribol. Int. 2007, 40, 1680-1695. [CrossRef]

22. Fischer, T.E. Tribochemistry. Annu. Rev. Mater. Sci. 1988, 18, 303-323. [CrossRef]

23. Juhasz, Z.; Opoczky, L.; Nogradi, M. Mechanical Activation of Minerals by Grinding: Pulverizing and Morphology of Particles; Ellis Horwood: Hemel Hempstead, UK, 1990.

24. Spikes, H. Stress-augmented thermal activation: Tribology feels the force. Friction 2018, 6, 1-31. [CrossRef]

25. Clarivate Analytics. Web of Science Core Collection; Clarivate Analytics: Philadelphia, PA, USA, 2017.

26. Achar, T.K.; Bose, A.; Mal, P. Mechanochemical synthesis of small organic molecules. Beilstein J. Org. Chem. 2017, 13, 1907-1931. [CrossRef]

27. Ahmadabadi, V.G.; Azghandi, S.H.M.; Khaki, J.V.; Haddad-Sabzevar, M. Synthesis of nano-structure molybdenum disilicide from primary mixture of $\mathrm{MoO} 3+\mathrm{Si}+\mathrm{Al}$ through mechanochemical reactions. Int. J. Refract. Met. Hard Mater. 2013, 41, 121-127. [CrossRef]

28. Suchanek, W.L.; Shuk, P.; Byrappa, K.; Riman, R.E.; TenHuisen, K.S.; Janas, V.F. Mechanochemical-hydrothermal synthesis of carbonated apatite powders at room temperature. Biomaterials 2002, 23, 699-710. [CrossRef]

29. Espinoza-Gonzalez, R.; Vega, E.; Tamayo, R.; Criado, J.M.; Dianez, M.J. Mechanochemical Processing of CaCu3Ti4O12 with Giant Dielectric Properties. Mater. Manuf. Process. 2014, 29, 1179-1183. [CrossRef]

30. Liu, X.; Wang, J.; Ding, J.; Chen, M.S.; Shen, Z.X. The effects of mechanical activation in synthesizing ultrafine barium ferrite powders from co-precipitated precursors. J. Mater. Chem. 2000, 10, 1745-1749. [CrossRef]

31. Wu, E.; Campbell, S.; Kaczmarek, W. A Mössbauer effect study of ball-milled strontium ferrite. J. Magn. Magn. Mater. 1998, 177, 255-256. [CrossRef]

32. A Ăgoğulları, D.; Balcı, Ö.; Öveçoğlu, M.; Duman, I. Preparation of LaB6 Powders via Calciothermic Reduction using Mechanochemistry and Acid Leaching. KONA Powder Part. J. 2016, 33, 203-218. [CrossRef]

33. Qu, J.; Zhang, Q.; Li, X.; He, X.; Song, S. Mechanochemical approaches to synthesize layered double hydroxides: A review. Appl. Clay Sci. 2016, 119, 185-192. [CrossRef] 
34. Chen, Y.; Marsh, M.; Williams, J.; Ninham, B.W. Production of rutile from ilmenite by room temperature ball-milling-induced sulphurisation reaction. J. Alloy. Compd. 1996, 245, 54-58. [CrossRef]

35. Radev, D.D.; Marinov, M. Comparative studies on the high-temperature and mechanochemical synthesis of titaniun diboride. Comptes Rendus De L Acad. Bulg. Des Sci. 2013, 66, 827-832. [CrossRef]

36. Puclin, T.; Kaczmarek, W.; Ninham, B.W. Mechanochemical processing of ZrSiO4. Mater. Chem. Phys. 1995, 40,73-81. [CrossRef]

37. Bujňáková, Z.; Baláz, P.; Caplovicova, M.; Čaplovič, L.; Kováč, J.; Zorkovská, A. Mechanochemical synthesis of InAs nanocrystals. Mater. Lett. 2015, 159, 474-477. [CrossRef]

38. Kristl, M.; Gyergyek, S.; Srt, N.; Ban, I. Mechanochemical Route for the Preparation of Nanosized Aluminum and Gallium Sulfide and Selenide. Mater. Manuf. Process. 2016, 31, 1608-1612. [CrossRef]

39. Baláž, P.; Hegedüs, M.; Achimovičová, M.; Baláž, M.; Tešinský, M.; Dutková, E.; Kanuchova, M.; Briančin, J. Semi-industrial Green Mechanochemical Syntheses of Solar Cell Absorbers Based on Quaternary Sulfides. ACS Sustain. Chem. Eng. 2018, 6, 2132-2141. [CrossRef]

40. Balaz, P.; Poughahramani, P.; Dutkova, E.; Turianicova, E.; Kovac, J.; Satka, A. Mechanochemistry in Preparation of Nanocrystalline Semiconductors. Curr. Top. Solid State Phys. 2008, 5, 3756-3758.

41. Chin, P.; Ding, J.; Yi, J.; Liu, B. Synthesis of FeS2 and FeS nanoparticles by high-energy mechanical milling and mechanochemical processing. J. Alloy. Compd. 2005, 390, 255-260. [CrossRef]

42. Huitink, D.; Peng, L.; Ribeiro, R.; Liang, H. In situobservation of stress-induced Au-Si phase transformation. Appl. Phys. Lett. 2009, 94, 183111. [CrossRef]

43. Baláž, M.; Daneu, N.; Balážová, L'.; Dutková, E.; Tkáčiková, L.; Briančin, J.; Vargová, M.; Balážová, M.; Zorkovská, A.; Baláž, P. Bio-mechanochemical synthesis of silver nanoparticles with antibacterial activity. Adv. Powder Technol. 2017, 28, 3307-3312. [CrossRef]

44. Bujňáková, Z.; Dutková, E.; Kello, M.; Mojzis, J.; Baláž, M.; Baláž, P.; Shpotyuk, O. Mechanochemistry of Chitosan-Coated Zinc Sulfide (ZnS) Nanocrystals for Bio-imaging Applications. Nanoscale Res. Lett. 2017, 12, 328. [CrossRef] [PubMed]

45. Kasprzak, A.; Bystrzejewski, M.; Koszytkowska-Stawinska, M.; Popławska, M. Grinding-induced functionalization of carbon-encapsulated iron nanoparticles. Green Chem. 2017, 19, 3510-3514. [CrossRef]

46. Salari, M.; Khoie, S.M.; Marashi, P.; Rezaee, M. Synthesis of $\mathrm{TiO}_{2}$ nanoparticles via a novel mechanochemical method. J. Alloy. Compd. 2009, 469, 386-390. [CrossRef]

47. Dunnill, C.W.; Aiken, Z.; Kafizas, A.; Pratten, J.; Wilson, M.; Morgan, D.J.; Parkin, I.P. White light induced photocatalytic activity of sulfur-doped $\mathrm{TiO}_{2}$ thin films and their potential for antibacterial application. J. Mater. Chem. 2009, 19, 8747-8754. [CrossRef]

48. Kotta, A.; Ansari, S.A.; Parveen, N.; Fouad, H.; Alothman, O.Y.; Khaled, U.; Seo, H.K.; Ansari, Z.A.; Ansari, S.G. Mechanochemical synthesis of melamine doped $\mathrm{TiO}_{2}$ nanoparticles for dye sensitized solar cells application. J. Mater. Sci. Mater. Electron. 2018, 29, 9108-9116. [CrossRef]

49. Dutková, E.; Čaplovičová, M.; Škorvánek, I.; Baláž, M.; Zorkovská, A.; Baláž, P.; Čaplovič, L. Structural, surface and magnetic properties of chalcogenide Co9S8 nanoparticles prepared by mechanochemical synthesis. J. Alloy. Compd. 2018, 745, 863-867. [CrossRef]

50. Ameri, B.; Davarani, S.S.H.; Roshani, R.; Moazami, H.R.; Tadjarodi, A. A flexible mechanochemical route for the synthesis of copper oxide nanorods/nanoparticles/nanowires for supercapacitor applications: The effect of morphology on the charge storage ability. J. Alloy. Compd. 2017, 695, 114-123. [CrossRef]

51. Vazquéz-Olmos, A.; Sánchez-Vergara, M.; Osorio, A.-L.F.; Hernández-García, A.; Sato-Berrú, R.Y.; Álvarez-Bada, J.R. Mechanochemical Synthesis of YFeO3 Nanoparticles: Optical and Electrical Properties of Thin Films. J. Clust. Sci. 2018, 29, 225-233. [CrossRef]

52. Lin, Y.; Watson, K.A.; Ghose, S.; Smith, J.J.G.; Williams, T.V.; Crooks, R.E.; Cao, W.; Connell, J.W. Direct Mechanochemical Formation of Metal Nanoparticles on Carbon Nanotubes. J. Phys. Chem. C 2009, 113, 14858-14862. [CrossRef]

53. Xu, J.; Jeon, I.Y.; Choi, H.J.; Kim, S.J.; Shin, S.H.; Park, N.; Dai, L.M.; Baek, J.B. Metalated graphene nanoplatelets and their uses as anode materials for lithium-ion batteries. 2D Mater. 2016, 4, 014002. [CrossRef]

54. Huang, Y.-H.; Lo, W.-S.; Kuo, Y.-W.; Chen, W.-J.; Linbc, C.-H.; Shieh, F.-K. Green and rapid synthesis of zirconium metal-organic frameworks via mechanochemistry: UiO-66 analog nanocrystals obtained in one hundred seconds. Chem. Commun. 2017, 53, 5818-5821. [CrossRef] [PubMed] 
55. Li, H.; Eddaoudi, M.; O'Keeffe, M.; Yaghi, O.M. Design and synthesis of an exceptionally stable and highly porous metal-organic framework. Nature 1999, 402, 276-279. [CrossRef]

56. Braga, D.; Maini, L.; Polito, M.; Mirolo, L.; Grepioni, F. Mechanochemical assembly of hydrogen bonded organic-organometallic solid compounds. Chem. Commun. 2002, 24, 2960-2961. [CrossRef] [PubMed]

57. Braga, D.; Giaffreda, S.L.; Grepioni, F.; Pettersen, A.; Maini, L.; Curzi, M.; Polito, M. Mechanochemical preparation of molecular and supramolecular organometallic materials and coordination networks. Dalton Trans. 2006, 37, 1249-1263. [CrossRef]

58. Kaupp, G. Solid-state molecular syntheses: Complete reactions without auxiliaries based on the new solid-state mechanism. Crystengcomm 2003, 5, 117-133. [CrossRef]

59. Quaresma, S.; Andre, V.; Fernandes, A.; Duarte, M.T. Mechanochemistry-A green synthetic methodology leading to metallodrugs, metallopharmaceuticals and bio-inspired metal-organic frameworks. Inorg. Chim. Acta 2017, 455, 309-318. [CrossRef]

60. Bond, A.D. What is a co-crystal? Crystengcomm 2007, 9, 833-834. [CrossRef]

61. Oburn, S.M.; Ray, O.A.; MacGillivray, L.R. Elusive Nonsolvated Cocrystals of Aspirin: Two Polymorphs with Bipyridine Discovered with the Assistance of Mechanochemistry. Cryst. Growth Des. 2018, 18, 2495-2501. [CrossRef]

62. Hu, Y.; Gniado, K.; Erxleben, A.; McArdle, P. Mechanochemical Reaction of Sulfathiazole with Carboxylic Acids: Formation of a Cocrystal, a Salt, and Coamorphous Solids. Cryst. Growth Des. 2014, 14, 803-813. [CrossRef]

63. Braga, D.; Grepioni, F.; Lampronti, G.I.; Maini, L.; Turrina, A. Ionic Co-crystals of Organic Molecules with Metal Halides: A New Prospect in the Solid Formulation of Active Pharmaceutical Ingredients. Cryst. Growth Des. 2011, 11, 5621-5627. [CrossRef]

64. Shan, N.; Toda, F.; Jones, W. Mechanochemistry and co-crystal formation: Effect of solvent on reaction kinetics. Chem. Commun. 2002, 20, 2372-2373. [CrossRef]

65. Batzdorf, L.; Zientek, N.; Rump, D.; Fischer, F.; Maiwald, M.; Emmerling, F. Make and break—Facile synthesis of cocrystals and comprehensive dissolution studies. J. Mol. Struct. 2017, 1133, 18-23. [CrossRef]

66. Fischer, F.; Wenzel, K.J.; Rademann, K.; Emmerling, F. Quantitative determination of activation energies in mechanochemical reactions. Phys. Chem. Chem. Phys. 2016, 18, 23320-23325. [CrossRef] [PubMed]

67. De Souza, V.P.; Oliveira, C.K.; de Souza, T.M.; Menezes, P.H.; Alves, S.; Longo, R.L.; Malvestiti, I. A Green Approach for Allylations of Aldehydes and Ketones: Combining Allylborate, Mechanochemistry and Lanthanide Catalyst. Molecules 2016, 21, 1539. [CrossRef]

68. Hernandez, J.G.; Ardila-Fierro, K.J.; Crawford, D.; James, S.L.; Bolm, C. Mechanoenzymatic peptide and amide bond formation. Green Chem. 2017, 19, 2620-2625. [CrossRef]

69. Nicholls, M.A.; Do, T.; Norton, P.R.; Kasrai, M.; Bancroft, G.M. Review of the lubrication of metallic surfaces by zinc dialkyl-dithlophosphates. Tribol. Int. 2005, 38, 15-39. [CrossRef]

70. Spikes, H. The history and mechanisms of ZDDP. Tribol. Lett. 2004, 17, 469-489. [CrossRef]

71. Campbell, K.L.; Sidebottom, M.A.; Atkinson, C.C.; Babuska, T.F.; Kolanovic, C.A.; Boulden, B.J.; Junk, C.P.; Krick, B.A. Ultralow Wear PTFE-Based Polymer Composites-The Role of Water and Tribochemistry. Macromolecules 2019, 52, 5268-5277. [CrossRef]

72. Montei, E.L.; Ballarotto, V.W.; Little, M.E.; Kordesch, M.E. Applications for small photoelectron emission microscopes. J. Electron Spectrosc. Relat. Phenom. 1997, 84, 129-136. [CrossRef]

73. Harris, M.D.; Berkebile, S.P.; Murthy, N.K.; Voevodin, A.A. In-situ instrumentation to observe transient tribological effects in high sliding speed unlubricated contacts. Wear 2020, 442, 203111. [CrossRef]

74. Uzarevic, K.; Halasz, I.; Friscic, T. Real-Time and In Situ Monitoring of Mechanochemical Reactions: A New Playground for All Chemists. J. Phys. Chem. Lett. 2015, 6, 4129-4140. [CrossRef]

75. Gracin, D.; Strukil, V.; Friscic, T.; Halasz, I.; Uzarevic, K. Laboratory Real-Time and In Situ Monitoring of Mechanochemical Milling Reactions by Raman Spectroscopy. Angew. Chem. Int. Ed. 2014, 53, 6193-6197. [CrossRef] [PubMed]

76. Harrison, J.A.; Gao, G.; Schall, J.D.; Knippenberg, M.T.; Mikulski, P.T. Friction between solids. Philos. Trans. R. Soc. A Math. Phys. Eng. Sci. 2008, 366, 1469-1495. [CrossRef] [PubMed]

77. Archard, J.F. The temperature of rubbing surfaces. Wear 1959, 2, 438-455. [CrossRef]

78. Kajdas, C. General Approach to Mechanochemistry and Its Relation to Tribochemistry. In Tribology in Enginering; Pihtili, H., Ed.; IntechOpen: London, UK, 2013; pp. 209-240. 
79. Bartenev, G.M.; Lavrentjev, V.V.; Konstantinova, N.A. Actual contact area and friction properties of elastomers under frictional contact with solid surfaces. Wear 1971, 18, 439-448. [CrossRef]

80. Watkins, R.C. The antiwear mechanism of zddps. 2. Tribol. Int. 1982, 15, 13-15. [CrossRef]

81. Mori, S.; Shitara, Y. Tribochemical activation of gold surface by scratching. Appl. Surf. Sci. 1994, 78, $269-273$. [CrossRef]

82. Philippon, D.; De Barros-Bouchet, M.I.; Le Mogne, T.; Lerasle, O.; Bouffet, A.; Martin, J.M. Role of nascent metallic surfaces on the tribochemistry of phosphite lubricant additives. Tribol. Int. 2011, 44, 684-691. [CrossRef]

83. Kauzmann, W.; Eyring, H. The Viscous Flow of Large Molecules. J. Am. Chem. Soc. 1940, 62, $3113-3125$. [CrossRef]

84. Bell, G.I. Theoretical-models for the specific adhesion of cells to cells or to surfaces. Adv. Appl. Probab. 1980, 12, 566-567. [CrossRef]

85. Evans, E. Energy landscapes of biomolecular adhesion and receptor anchoring at interfaces explored with dynamic force spectroscopy. Faraday Discuss. 1998, 111, 1-16. [CrossRef] [PubMed]

86. Konda, S.S.M.; Brantley, J.N.; Bielawski, C.W.; Makarov, D.E. Chemical reactions modulated by mechanical stress: Extended Bell theory. J. Chem. Phys. 2011, 135, 164103. [CrossRef]

87. Krupicka, M.; Marx, D. Disfavoring Mechanochemical Reactions by Stress-Induced Steric Hindrance. J. Chem. Theory Comput. 2015, 11, 841-846. [CrossRef] [PubMed]

88. Tian, Y.C.; Boulatov, R. Comparison of the predictive performance of the Bell-Evans, Taylor-expansion and statistical-mechanics models of mechanochemistry. Chem. Commun. 2013, 49, 4187-4189. [CrossRef]

89. Hermes, M.; Boulatov, R. The Entropic and Enthalpic Contributions to Force-Dependent Dissociation Kinetics of the Pyrophosphate Bond. J. Am. Chem. Soc. 2011, 133, 20044-20047. [CrossRef]

90. Akbulatov, S.; Boulatov, R. Experimental Polymer Mechanochemistry and its Interpretational Frameworks. Chemphyschem 2017, 18, 1422-1450. [CrossRef]

91. Hyeon, C.; Thirumalai, D. Measuring the energy landscape roughness and the transition state location of biomolecules using single molecule mechanical unfolding experiments. J. Phys. Condens. Matter 2007, 19, 113101. [CrossRef]

92. Bustamante, C.; Chemla, Y.R.; Forde, N.R.; Izhaky, D. Mechanical processes in biochemistry. Annu. Rev. Biochem. 2004, 73, 705-748. [CrossRef]

93. Ribas-Arino, J.; Shiga, M.; Marx, D. Understanding Covalent Mechanochemistry. Angew. Chem. Int. Ed. 2009, 48, 4190-4193. [CrossRef]

94. Kajdas, C.; Hiratsuka, K. Tribochemistry, tribocatalysis, and the negative-ion-radical action mechanism. Proc. Inst. Mech. Eng. Part J J. Eng. Tribol. 2009, 223, 827-848. [CrossRef]

95. Kajdas, C.K. Importance of the triboemission process for tribochemical reaction. Tribol. Int. 2005, 38, 337-353. [CrossRef]

96. Nevshupa, R. Triboemission: An attempt of developing a generalized classification. In Tribology Science and Application; Herman, M., Ed.; Vienna Publishing House, CUN PAN: Warsaw, Poland, 2004; pp. 11-25.

97. Ohuchi, H.; Enomoto, Y. Frictional heat-stimulated exo-electron emission from alumina sliding surfaces. Appl. Phys. Lett. 1995, 66, 1205-1207. [CrossRef]

98. Nakayama, K.; Fujiwara, T.; Hashimoto, H. Exoelectron measurement apparatus incorporated in a scanning electron-microscope. J. Phys. E Sci. Instrum. 1984, 17, 1199-1203. [CrossRef]

99. Nakayama, K.; Hashimoto, H. Triboemission of charged-particles and photons from wearing ceramic surfaces in various gases. Tribol. Trans. 1992, 35, 643-650. [CrossRef]

100. Huitink, D. Mechanochemical Fabrication and Characterization of Novel Low-Dimensional Materials. Ph.D. Thesis, Texas A\&M University, College Station, TX, USA, 2011.

101. Wang, Y.; Yamada, N.; Xu, J.X.; Zhang, J.; Chen, Q.; Ootani, Y.; Higuchi, Y.; Ozawa, N.; Bouchet, M.I.D.; Martin, J.M.; et al. Triboemission of hydrocarbon molecules from diamond-like carbon friction interface induces atomic-scale wear. Sci. Adv. 2019, 5, eaax9301. [CrossRef] [PubMed]

102. Dickinson, J.T.; Jensen, L.C.; Jahanlatibari, A. Fracto-emission-the role of charge separation. J. Vac. Sci. Technol. A Vac. Surf. Film. 1984, 2, 1112-1116. [CrossRef]

103. Ciniero, A.; Le Rouzic, J.; Baikie, I.; Reddyhoff, T. The origins of triboemission-Correlating wear damage with electron emission. Wear 2017, 374, 113-119. [CrossRef] 
104. Erdemir, A.; Ramirez, G.; Eryilmaz, O.L.; Narayanan, B.; Liao, Y.F.; Kamath, G.; Sankaranarayanan, S. Carbon-based tribofilms from lubricating oils. Nature 2016, 536, 67-71. [CrossRef]

105. Adams, H.L.; Garvey, M.T.; Ramasamy, U.S.; Ye, Z.J.; Martini, A.; Tysoe, W.T. Shear-Induced Mechanochemistry: Pushing Molecules Around. J. Phys. Chem. C 2015, 119, 7115-7123. [CrossRef]

106. Dorr, N.; Brenner, J.; Ristic, A.; Ronai, B.; Besser, C.; Pejakovic, V.; Frauscher, M. Correlation between Engine Oil Degradation, Tribochemistry, and Tribological Behavior with Focus on ZDDP Deterioration. Tribol. Lett. 2019, 67, 62. [CrossRef]

107. Bancroft, G.M.; Kasrai, M.; Fuller, M.; Yin, Z.; Fyfe, K.; Tan, K.H. Mechanisms of tribochemical film formation: Stability of tribo- and thermally-generated ZDDP films. Tribol. Lett. 1997, 3, 47-51. [CrossRef]

108. Gosvami, N.N.; Lahouij, I.; Ma, J.; Carpick, R.W. Nanoscale in situ study of ZDDP tribofilm growth at aluminum-based interfaces using atomic force microscopy. Tribol. Int. 2020, 143, 106075. [CrossRef]

109. Ghanbarzadeh, A.; Parsaeian, P.; Morina, A.; Wilson, M.C.T.; van Eijk, M.C.P.; Nedelcu, I.; Dowson, D.; Neville, A. A Semi-deterministic Wear Model Considering the Effect of Zinc Dialkyl Dithiophosphate Tribofilm. Tribol. Lett. 2016, 61, 12. [CrossRef]

110. Onodera, T.; Morita, Y.; Suzuki, A.; Sahnoun, R.; Koyama, M.; Tsuboi, H.; Hatakeyama, N.; Endou, A.; Takaba, H.; Kubo, M.; et al. A theoretical investigation on the abrasive wear prevention mechanism of ZDDP and ZP tribofilms. Appl. Surf. Sci. 2008, 254, 7976-7979. [CrossRef]

111. Wan, S.H.; Tieu, A.K.; Zhu, Q.; Zhu, H.T.; Cui, S.G.; Mitchell, D.R.G.; Kong, C.; Cowie, B.; Denman, J.A.; Liu, R. Chemical nature of alkaline polyphosphate boundary film at heated rubbing surfaces. Sci. Rep. 2016, 6, 26008. [CrossRef]

112. Tieu, A.K.; Kong, N.; Wan, S.H.; Zhu, H.T.; Zhu, Q.; Mitchell, D.R.G.; Kong, C. The Influence of Alkali Metal Polyphosphate on the Tribological Properties of Heavily Loaded Steel on Steel Contacts at Elevated Temperatures. Adv. Mater. Interfaces 2015, 2, 1500032. [CrossRef]

113. Erdemir, A.; Donnet, C. Tribology of diamond-like carbon films: Recent progress and future prospects. J. Phys. D Appl. Phys. 2006, 39, R311-R327. [CrossRef]

114. Wu, H.X.; Khan, A.M.; Johnson, B.; Sasikumar, K.; Chung, Y.W.; Wang, Q.J. Formation and Nature of Carbon-Containing Tribofilms. ACS Appl. Mater. Interfaces 2019, 11, 16139-16146. [CrossRef]

115. Johnson, B.; Wu, H.X.; Desanker, M.; Pickens, D.; Chung, Y.W.; Wang, Q.J. Direct Formation of Lubricious and Wear-Protective Carbon Films from Phosphorus- and Sulfur-Free Oil-Soluble Additives. Tribol. Lett. 2018, 66, 2. [CrossRef]

116. Xu, J.; Nian, J.Y.; Wang, P.; Guo, Z.G.; Liu, W.M. Elastic Lubricious Effect of Solidlike Boundary Films in Oil-Starvation Lubrication. J. Phys. Chem. C 2019, 123, 1677-1691. [CrossRef]

117. Shen, A.; Caldwell, D.; Ma, A.W.K.; Dardona, S. Direct write fabrication of high-density parallel silver interconnects. Addit. Manuf. 2018, 22, 343-350. [CrossRef]

118. Schindler, S.; Vollnhals, F.; Halbig, C.E.; Marbach, H.; Steinruck, H.P.; Papp, C.; Eigler, S. Focused electron beam based direct-write fabrication of graphene and amorphous carbon from oxo-functionalized graphene on silicon dioxide. Phys. Chem. Chem. Phys. 2017, 19, 2683-2686. [CrossRef] [PubMed]

119. Shawrav, M.M.; Taus, P.; Wanzenboeck, H.D.; Schinnerl, M.; Stoger-Pollach, M.; Schwarz, S.; Steiger-Thirsfeld, A.; Bertagnolli, E. Highly conductive and pure gold nanostructures grown by electron beam induced deposition. Sci. Rep. 2016, 6, 34003. [CrossRef] [PubMed]

120. Carlton, H.; Kundu, S.; Huitink, D. Tribochemical formation of high aspect ratio graphitic structures via platinum nanoparticle catalysts. Diam. Relat. Mater. 2019, 94, 101-109. [CrossRef]

121. Yun, Y.J.; Ju, J.; Lee, J.H.; Moon, S.H.; Park, S.J.; Kim, Y.H.; Hong, W.G.; Ha, D.H.; Jang, H.; Lee, G.H.; et al. Highly Elastic Graphene-Based Electronics Toward Electronic Skin. Adv. Funct. Mater. 2017, 27, 1701513. [CrossRef]

122. Khan, U.; Kim, T.H.; Ryu, H.; Seung, W.; Kim, S.W. Graphene Tribotronics for Electronic Skin and Touch Screen Applications. Adv. Mater. 2017, 29, 1603544. [CrossRef]

123. Zhai, W.Z.; Srikanth, N.; Kong, L.B.; Zhou, K. Carbon nanomaterials in tribology. Carbon 2017, 119, $150-171$. [CrossRef]

124. Berman, D.; Mutyala, K.C.; Srinivasan, S.; Sankaranarayanan, S.; Erdemir, A.; Shevchenko, E.V.; Sumant, A.V. Iron-Nanoparticle Driven Tribochemistry Leading to Superlubric Sliding Interfaces. Adv. Mater. Interfaces 2019, 6, 1901416. [CrossRef] 
125. Li, B.; Wang, X.; Liu, W.; Xue, Q. Tribochemistry and antiwear mechanism of organic-inorganic nanoparticles as lubricant additives. Tribol. Lett. 2006, 22, 79-84. [CrossRef]

126. Berman, D.; Narayanan, B.; Cherukara, M.J.; Sankaranarayanan, S.; Erdemir, A.; Zinovev, A.; Sumant, A.V. Operando tribochemical formation of onion-like-carbon leads to macroscale superlubricity. Nat. Commun. 2018, 9, 1164. [CrossRef]

127. Wang, K.; Kundu, S.; Lee, H.; Liang, H. Formation of Silver Nanochains through Mechanoactivation. J. Phys. Chem. C 2009, 113, 8112-8117. [CrossRef]

128. Tripathy, B.S.; Furey, M.J.; Kajdas, C. Mechanism of wear reduction of alumina by tribopolymerization. Wear 1995, 181, 138-147. [CrossRef]

129. Yang, J.; Qi, Y.; Kim, H.D.; Rappe, A.M. Mechanism of Benzene Tribopolymerization on the RuO2(110) Surface. Phys. Rev. Appl. 2018, 9, 044038. [CrossRef]

130. Yeon, J.; He, X.; Martini, A.; Kim, S.H. Mechanochemistry at Solid Surfaces: Polymerization of Adsorbed Molecules by Mechanical Shear at Tribological Interfaces. ACS Appl. Mater. Interfaces 2017, 9, 3142-3148. [CrossRef]

131. He, X.; Kim, S.H. Surface Chemistry Dependence of Mechanochemical Reaction of Adsorbed Molecules-An Experimental Study on Tribopolymerization of alpha-Pinene on Metal, Metal Oxide, and Carbon Surfaces. Langmuir 2018, 34, 2432-2440. [CrossRef] [PubMed]

132. He, X.; Pollock, A.; Kim, S.H. Effect of Gas Environment on Mechanochemical Reaction: A Model Study with Tribo-Polymerization of -Pinene in Inert, Oxidative, and Reductive Gases. Tribol. Lett. 2019, 67, 25. [CrossRef]

133. He, X.; Kim, S.H. Mechanochemistry of Physisorbed Molecules at Tribological Interfaces: Molecular Structure Dependence of Tribochemical Polymerization. Langmuir 2017, 33, 2717-2724. [CrossRef]

134. Ponomarenko, A.G.; Kolesnikov, I.V.; Bicherov, A.A.; Shiryaeva, T.A.; Nikogosov, M.V.; Boiko, M.V. Influence of Formation of Nanocomposite Films on Friction Surfaces on the Antifriction Properties of Transmission Oil. J. Frict. Wear 2020, 41, 247-251. [CrossRef]

135. Ponomarenko, A.G.; Boiko, M.V.; Kalmykova, A.G.; Boiko, T.G.; Shiryaeva, T.A.; Burlov, A.S. Tribochemical processes in engine oil with copper nanoparticles and azomethine ligand. J. Frict. Wear 2016, 37, 435-440. [CrossRef]

136. Svahn, F.; Csillag, S. Formation of Low-Friction Particle/Polymer Composite Tribofilms by Tribopolymerization. Tribol. Lett. 2011, 41, 387-393. [CrossRef]

137. Gotor, F.J.; Achimovicova, M.; Real, C.; Balaz, P. Influence of the milling parameters on the mechanical work intensity in planetary mills. Powder Technol. 2013, 233, 1-7. [CrossRef]

138. Ding, J.; Tsuzuki, T.; McCormick, P.G.; Street, R. Ultrafine Co and Ni particles prepared by mechanochemical processing. J. Phys. D Appl. Phys. 1996, 29, 2365-2369. [CrossRef]

139. Tcherdyntsev, V.V.; Senatov, F.S.; Kaloshkin, S.D.; Kuznetsov, D.V. Mechanochemical Synthesis of Ultradispersed Powders of Manganese and Zinc Oxides. Inorg. Mater. Appl. Res. 2009, 2, 5-9. [CrossRef]

140. Crawford, D.E.; Casaban, J. Recent Developments in Mechanochemical Materials Synthesis by Extrusion. Adv. Mater. 2016, 28, 5747-5754. [CrossRef]

141. Crawford, D.E.; Miskimmin, C.K.G.; Albadarin, A.B.; Walker, G.; James, S.L. Organic synthesis by Twin Screw Extrusion (TSE): Continuous, scalable and solvent-free. Green Chem. 2017, 19, 1507-1518. [CrossRef]

142. Gryczke, A.; Schminke, S.; Maniruzzaman, M.; Beck, J.; Douroumis, D. Development and evaluation of orally disintegrating tablets (ODTs) containing Ibuprofen granules prepared by hot melt extrusion. Colloids Surf. B Biointerfaces 2011, 86, 275-284. [CrossRef]

143. Wang, K.; Rangel, N.L.; Kundu, S.; Sotelo, J.C.; Tovar, R.M.; Seminario, J.M.; Liang, H. Switchable Molecular Conductivity. J. Am. Chem. Soc. 2009, 131, 10447-10451. [CrossRef]

144. Chen, Y.; Jha, S.; Raut, A.; Parkinson, D.Y.; Zhang, B.; Elwany, A.; Liang, H. Sub-surface deformation in rolling contact of 3D printed lattice structured AlSi alloy. 3D Print. Addit. Manuf. 2020, in press.

(C) 2020 by the authors. Licensee MDPI, Basel, Switzerland. This article is an open access article distributed under the terms and conditions of the Creative Commons Attribution (CC BY) license (http://creativecommons.org/licenses/by/4.0/). 